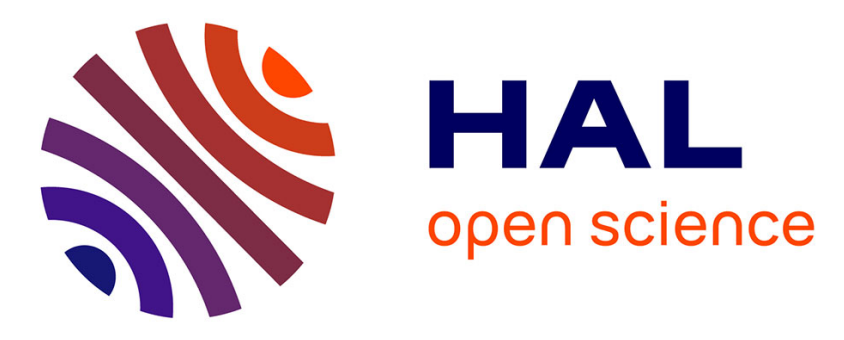

\title{
Pseudo-merohedral twinning in monoclinic crystals of wild-type human brain neuroglobin
}

Djemel Hamdane, Christophe Lechauve, Michael C Marden, Béatrice

Golinelli-Pimpaneau

\section{To cite this version:}

Djemel Hamdane, Christophe Lechauve, Michael C Marden, Béatrice Golinelli-Pimpaneau. Pseudo-merohedral twinning in monoclinic crystals of wild-type human brain neuroglobin. Acta crystallographica Section D: Structural biology [1993-..], 2009, 65 (4), pp.388 - 392. $10.1107 / \mathrm{s} 0907444909003382$. hal-03280005

\section{HAL Id: hal-03280005 https://hal.science/hal-03280005}

Submitted on 6 Jul 2021

HAL is a multi-disciplinary open access archive for the deposit and dissemination of scientific research documents, whether they are published or not. The documents may come from teaching and research institutions in France or abroad, or from public or private research centers.
L'archive ouverte pluridisciplinaire HAL, est destinée au dépôt et à la diffusion de documents scientifiques de niveau recherche, publiés ou non, émanant des établissements d'enseignement et de recherche français ou étrangers, des laboratoires publics ou privés. 
Acta Crystallographica Section D

\section{Biological}

Crystallography

ISSN 0907-4449

Editors: E. N. Baker and Z. Dauter

\section{Pseudo-merohedral twinning in monoclinic crystals of wild-type human brain neuroglobin}

\section{Djemel Hamdane, Christophe Lechauve, Michael C. Marden and Béatrice Golinelli-Pimpaneau}

Acta Cryst. (2009). D65, 388-392

Copyright (C) International Union of Crystallography

Author(s) of this paper may load this reprint on their own web site or institutional repository provided that this cover page is retained. Republication of this article or its storage in electronic databases other than as specified above is not permitted without prior permission in writing from the IUCr.

For further information see http://journals.iucr.org/services/authorrights.html

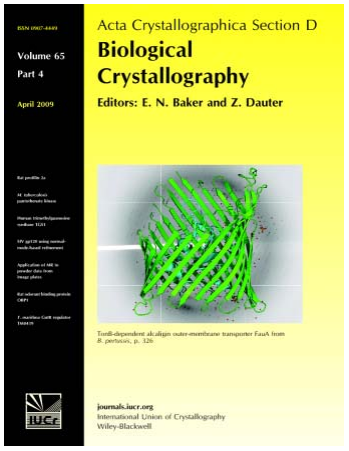

Acta Crystallographica Section D: Biological Crystallography welcomes the submission of papers covering any aspect of structural biology, with a particular emphasis on the structures of biological macromolecules and the methods used to determine them. Reports on new protein structures are particularly encouraged, as are structure-function papers that could include crystallographic binding studies, or structural analysis of mutants or other modified forms of a known protein structure. The key criterion is that such papers should present new insights into biology, chemistry or structure. Papers on crystallographic methods should be oriented towards biological crystallography, and may include new approaches to any aspect of structure determination or analysis.

Crystallography Journals Online is available from journals.iucr.org 
Acta Crystallographica Section D

Biological

Crystallography

ISSN 0907-4449

\section{Djemel Hamdane, ${ }^{a}$ Christophe Lechauve, ${ }^{b}$ Michael C. Marden ${ }^{b}$ and Béatrice Golinelli- Pimpaneau $^{\mathrm{a} *}$}

a'Laboratoire d'Enzymologie et Biochimie Structurales, CNRS, 1 Avenue de la Terrasse, 91190 Gif-sur-Yvette, France, and ${ }^{\mathbf{b}}$ Inserm U779, Université Paris XI, 78 Rue du Général Leclerc, 94275 Le Kremlin-Bicêtre, France

Correspondence e-mail:

beatrice.golinelli@lebs.cnrs-gif.fr

Received 23 October 2008

Accepted 27 January 2009
C 2009 International Union of Crystallography Printed in Singapore - all rights reserved

\section{Pseudo-merohedral twinning in monoclinic crystals of wild-type human brain neuroglobin}

The purification, crystallization and successful structure determination by molecular replacement of wild-type human brain neuroglobin at $1.8 \AA$ resolution is reported. The apparent space group was orthorhombic $C 222_{1}$, but the real space group was monoclinic $P 2_{1}$, which resulted from twinning. Indeed, the unit-cell parameters, $a=31.2, b=139.1, c=31.2 \AA, \beta=102^{\circ}$, display $a$ fortuitously close to $c$ and twinning by the operator $l,-k, h$ occurs. Twinning was not evident from the initial analysis of intensity distribution, but pseudomerohedral twinning was revealed by the Padilla and Yeates test based on local intensity differences. A twinning fraction of 0.5 was determined in SHELXL, indicating a perfect hemihedrally twinned crystal. To date, this type of twinning has been reported in more than ten structures, which makes it quite a common case in proteins.

\section{Introduction}

Neuroglobin $(\mathrm{Ngb})$, a recently discovered intracellular globin in vertebrates (Burmester et al., 2000), is expressed in the brain (Burmester et al., 2000) as well as in other nerve tissues and, with the highest levels, in the retina (Schmidt et al., 2003). The function of $\mathrm{Ngb}$ is not fully understood. However, the increase of $\mathrm{Ngb}$ expression in neuron cultures upon oxygen deficiency indicates its probable role in the protection of cells against hypoxia (Sun et al., 2003; Greenberg et al., 2008). Ngb may have a myoglobin-like function, supplying the respiratory chain of neuronal mitochondria with oxygen. However, other physiological roles such as electron transfer, peroxidase activity, NO binding or NO detoxification, as observed for other haemoproteins, are also conceivable.

Although analysis of the amino-acid sequence of Ngb reveals little similarity to those of haemoglobin and myoglobin, Ngb shares many of the characteristics of the globins, such as reversible oxygen binding and an overall three-dimensional $\alpha$-helical globin scaffold (Pesce et $a l ., 2002,2003)$. Nonetheless, in the absence of oxygen $\mathrm{Ngb}$ displays a particular haem configuration characteristic of a hexacoordinated species, in which the distal and proximal histidines are bound to the $\mathrm{Fe}$ atom in addition to the four pyrrole $\mathrm{N}$ atoms of the haem (Dewilde et al., 2001; Pesce et al., 2003).

Uniquely in the globin family, human Ngb (NGB) possesses cysteine residues (Cys46 and Cys55 in positions CD7 and D5, respectively) that are capable of forming a disulfide bond which may influence the overall oxygen affinity (Hamdane et al., 2003, 2004). Indeed, it has been shown that NGB can switch between two forms (with low or high affinity for oxygen) depending on the redox state of the cysteines (Hamdane et al., 2003). Although the existence of a disulfide bond has been demonstrated in solution by various biophysical techniques (Hamdane et al., 2003, 2004, 2005; Vinck et al., 2004; Ishikawa et al., 2007), it has not yet been observed by X-ray crystallography, the three-dimensional structure of wild-type NGB being unknown. The reported difficulties in crystallizing wild-type NGB led to mutagenesis and crystallization of an NGB mutant in which Cys46, Cys55 and Cys120 were replaced by Gly, Ser and Ser, 
Table 1

Data-collection statistics for wild-type human neuroglobin in different space groups.

Values in parentheses are for the highest resolution shell.

\begin{tabular}{|c|c|c|c|c|c|}
\hline Space group & $P 1$ & $P 2_{1}$ & $C 2$ & $C 2(2 \mathrm{nd})$ & $C 222_{1}$ \\
\hline Unit-cell parameters $\left(\AA,^{\circ}\right)$ & $\begin{array}{l}a=31.5, b=31.4, c=140.9 \\
\quad \alpha=89.2, \beta=90.9, \gamma=102.1\end{array}$ & $\begin{array}{c}a=31.2, b=139.1, c=31.2 \\
\alpha=\gamma=90, \beta=102.0\end{array}$ & $\begin{array}{c}a=39.3, b=48.5, c=139.2 \\
\alpha=\gamma=90, \beta=90.1\end{array}$ & $\begin{array}{c}a=48.5, b=39.3, c=139.3 \\
\alpha=\gamma=90, \beta=90.1\end{array}$ & $\begin{array}{c}a=39.3, b=48.5, c=139.2, \\
\alpha=\beta=\gamma=90\end{array}$ \\
\hline Resolution & $30.76-1.8(1.9-1.8)$ & $30.50-1.8(1.89-1.8)$ & $30.53-1.8(1.89-1.8)$ & $30.56-1.8(1.89-1.8)$ & $30.53-1.8(1.89-1.8)$ \\
\hline No. of observations & 84776 & 88601 & 88665 & 88638 & 88191 \\
\hline No. of unique reflections & 45719 & 24102 & 24521 & 24668 & 12786 \\
\hline Compleness $(\%)$ & $93.6(80.9)$ & $99.5(96.6)$ & $99.7(98.0)$ & $99.4(96.3)$ & $100.0(100.0)$ \\
\hline$\langle I / \sigma(I)\rangle$ & $5.5(1.3)$ & $8.6(2.2)$ & $8.5(2.1)$ & $9.2(2.2)$ & $10.9(2.5)$ \\
\hline$R_{\text {merge }}$ & $0.134(0.623)$ & $0.116(0.577)$ & $0.113(0.589)$ & $0.101(0.589)$ & $0.138(0.808)$ \\
\hline Redundancy & $1.9(1.7)$ & $3.7(3.4)$ & $3.6(3.4)$ & $3.6(3.4)$ & $6.9(6.6)$ \\
\hline
\end{tabular}

Table 2

Molecular-replacement solutions with Phaser using data in the resolution range 40$2 \AA$.

\begin{tabular}{|c|c|c|c|c|c|c|}
\hline $\begin{array}{l}\text { Space } \\
\text { group }\end{array}$ & $\begin{array}{l}\text { Molecules } \\
\text { in the ASU }\end{array}$ & $\mathrm{LLG}^{\prime}$ & Clashes & $\begin{array}{l}Z \ddagger \\
\text { rotation }\end{array}$ & $\begin{array}{l}Z \ddagger \\
\text { translation }\end{array}$ & $\begin{array}{l}\text { Twinned } R / \\
R_{\text {free }} \S(\%)\end{array}$ \\
\hline$C 222_{1}$ & 1 & 190 & 8 & 9.6 & 11.8 & $48.3 / 48.6$ \\
\hline$C 2$ & 2 & 360 & 16 & 9.9 & $\begin{array}{r}8.9 \\
14\end{array}$ & $51.1 / 53.8$ \\
\hline$C 2$ (2nd) & 2 & 364 & 14 & $\begin{array}{l}10.4 \\
11.9 \\
10.5\end{array}$ & $\begin{array}{r}14.0 \\
6.5 \\
14.5\end{array}$ & $48.0 / 50.8$ \\
\hline$P 2_{1}$ & 2 & 348 & 0 & $\begin{array}{l}9.9 \\
9.2\end{array}$ & $\begin{array}{r}6.8 \\
13.7\end{array}$ & $46.7 / 48.4$ \\
\hline$P 1$ & 4 & 564 & 17 & $\begin{array}{r}7.8 \\
10.4 \\
9.2 \\
8.7\end{array}$ & $\begin{array}{r}100 \\
10.5 \\
15.4 \\
9.1\end{array}$ & $45.6 / 46.4$ \\
\hline
\end{tabular}

$\dagger$ Log-likelihood gain. $\$$ Number of standard deviations above the mean. $\S$ Before minimization in SHELXL.

respectively. In the crystal structure of the NGB mutant at $1.95 \AA$ resolution (Pesce et al., 2003), Gly46 and Ser55 are farther away than expected for a potential disulfide bond in the wild-type protein, strengthening the hypothesis of a major structural rearrangement in the CD loop in wild-type NGB as a result of disulfide-bond breakage/ formation between Cys46 and Cys55. This region is directly connected to the $\mathrm{E}$ helix, which holds the crucial distal histidine that coordinates the haem. It is clear that the mechanically driven force resulting from the reduction-oxidation of the CD-loop disulfide bond may be transferred to the haem-binding pocket through the E helix (Hamdane et al., 2003, 2004, 2005). This could constitute a potential mechanism by which NGB regulates oxygen binding, which explains the essential role of NGB in oxygen homeostasis of neuronal cells. Therefore, it became urgent to determine the crystal structure of wild-type NGB in order to obtain evidence that the disulfide bond actually forms. Here, we report the crystallization and successful structure determination by molecular replacement of wild-type NGB. The diffraction data exhibit evidence of pseudo-merohedral twinning, in which a $P 2_{1}$ monoclinic crystal emulates $C$-centred orthorhombic symmetry.

\section{Materials and methods}

\subsection{Protein expression and purification}

Expression of wild-type NGB was performed as described previously (Dewilde et al., 2001). Ammonium sulfate precipitation (30\% and $50 \%$ ) was used for purification as detailed in Dewilde et al. (2008). The ammonium sulfate pellet was dissolved in $50 \mathrm{~m} M$ Tris$\mathrm{HCl} \mathrm{pH} 8.5$ and dialyzed overnight against the same buffer. Using an ÄKTA purifier system (Amersham Biosciences), the sample was then loaded onto a HiTrap DEAE Sepharose column equilibrated with the same buffer and eluted with $50 \mathrm{~m} M \mathrm{NaCl}$. The concentrated material was loaded onto a Superose 12 HR 16/50 (Amersham Biosciences). The final purity of the pooled NGB fractions was checked on a $12 \%$ SDS-PAGE gel.

\subsection{Crystallization}

NGB at $10 \mathrm{mg} \mathrm{ml}^{-1}$ was crystallized by the hanging-drop procedure in $0.2 \mathrm{M}$ magnesium acetate tetrahydrate, $0.1 \mathrm{M}$ sodium cacodylate $\mathrm{pH} 6.5,20 \%$ PEG 8000 . Crystals were flash-frozen in a nitrogen stream at $100 \mathrm{~K}$ in the same solution containing 25\% PEG 8000 and $20 \%$ glycerol.

\subsection{Data collection and analysis}

A data set to $1.8 \AA$ resolution was collected on the PROXIMA1 beamline at the SOLEIL Synchrotron in Saint Aubin (France) and processed with XDS (Kabsch, 1993) and SCALA (Evans, 2006) (Table 1). The Stanley factor $\left\langle I^{2}\right\rangle /\langle|I|\rangle^{2}$ and the Wilson's diffraction distribution were obtained from TRUNCATE (Collaborative Computational Project, Number 4, 1994).

\subsection{Molecular replacement and refinement}

Since structure determination by molecular replacement should not be hindered by crystal twinning (Yeates, 1997; Breyer et al., 1999), it was carried out on the $P 2_{1}$ twinned data with Phaser (Storoni et al., 2004) using the atomic coordinates of residues 3-45 and 60-149 of the NGB mutant (PDB code 1oj6; Table 2). Self-rotation function analysis of the data processed in space group $P 2_{1}$ using $A M o R e$ showed the presence of a twofold axis perpendicular to the crystallographic $b$ axis, indicating possible higher (orthorhombic) space-group symmetry or the presence of a noncrystallographic (NCS) axis perpendicular to but not necessarily intersecting the unique $b$ axis. The correlation coefficient was $96 \%$ in the resolution range $15.0-3.5 \AA$ with a Patterson integration radius of $40 \AA$.

The initial steps of refinement against intensities were carried out using SHELXL97 (Sheldrick, 2008) including the twinning operator $(l,-k, h)(\mathrm{TWIN})$, the twin fraction (BASF, initially set to 0.5$)$ and noncrystallographic symmetry (NCS) restraints (NCSY). To calculate $R_{\text {free }}$, the test reflections were selected in thin resolution shells; in order to avoid possible correlations introduced by the twinning, all the twin-related pairs belonged to either the test set or the reference set.

\section{Results and discussion}

\subsection{Detection of twinning}

Twinning is a crystal-growth anomaly in which two or more crystals intergrow in different relative orientations to form a larger twinned 
Table 3

Different cases of pseudomerohedral twinning in monoclinic space groups.

\begin{tabular}{|c|c|c|c|c|}
\hline True space group & Pseudo space group & $\begin{array}{l}\text { Geometry of } \\
\text { unit-cell parameters }\end{array}$ & Twin operator & Protein \\
\hline$P 2_{1}$ & $P 222_{1}$ & $\beta=90^{\circ}$ & $h,-k,-l$ & $\begin{array}{l}\text { Cocaine hydrolytic Fab15A10 (Larsen et al., 2002) } \\
\alpha \text {-Amino-acid ester hydrolase (Barends \& Dijkstra, 2003) } \\
\text { PLP-dependent catalytic Fab15A9 (Golinelli-Pimpaneau, 2005) }\end{array}$ \\
\hline$P 2_{1}$ & $C 222_{1}$ & $a=c$ & $l,-k, h$ & $\begin{array}{l}\text { Deoxyhaemoglobin (Ito et al., 1995) } \\
50 \text { S ribosomal subunit (Ban et al., 1999) } \\
\text { GpD capsid-stabilizing protein of bacteriophage } \lambda \text { (Yang et al., 2000) } \\
\text { Orotidine-5'-monophosphate decarboxylase (Wittmann \& Rudolph, } \\
\quad 2007 \text { ) } \\
\text { Aclacinomycin oxidoreductase (Sultana et al., 2007) } \\
\text { Dihaem } c \text {-type cytochrome DHC2 (Heitmann \& Einsle, 2008) }\end{array}$ \\
\hline$P 2_{1}$ & $C 222_{1}$ & $c \cos \beta=-a / 2$ & $\begin{array}{r}-h,-k, h+l \text { or } \\
h,-k,-h-l\end{array}$ & $\begin{array}{l}\text { Peroxiredoxin } 5 \text { (Declercq \& Evrard, 2001) } \\
\text { Polymeric immunoglobulin-binding fragment (Hamburger et al., 2004) } \\
\gamma \delta \text { T-cell ligand T10 (Rudolph et al., 2004) }\end{array}$ \\
\hline$C 2$ & $F 222$ & $c \cos \beta=-a / 2$ & $-h,-k, h+l$ & $\begin{array}{l}\text { Acetyl coenzyme A synthetase (Lehtiö et al., 2005) } \\
\text { THATCH domain of HIP1R (Brett et al., 2006) }\end{array}$ \\
\hline
\end{tabular}

aggregate. In pseudo-merohedral twins, the twin operator relating the twin domains belongs to a higher crystal system than the structure. The diffraction spots from the different crystal domains most often completely overlap, so that twinning is not suspected from the diffraction pattern. Pseudo-merohedral twinning can occur in monoclinic crystal systems when the unit-cell parameters meet one of the following conditions: $c \cos \beta=-a / 2, b$ is close to $90^{\circ}$ or $a$ is close to $c$. Previously reported cases of pseudo-merohedral twinning in a monoclinic space group are listed in Table 3.

The data from the wild-type NGB crystal were processed in space groups $P 1, P 2_{1}, C 2$ and $C 222_{1}$ and tested for molecular replacement with Phaser (Table 1). Although plausible molecular-replacement solutions were found in the $C 222_{1}$ and $C 2$ space groups, they were abandoned because of numerous bad contacts. The space group was assigned as $P 2_{1}$ given the low $R_{\text {merge }}$ value, the presence of a twofold screw axis established from analysis of the systematic absences and the success of molecular replacement.

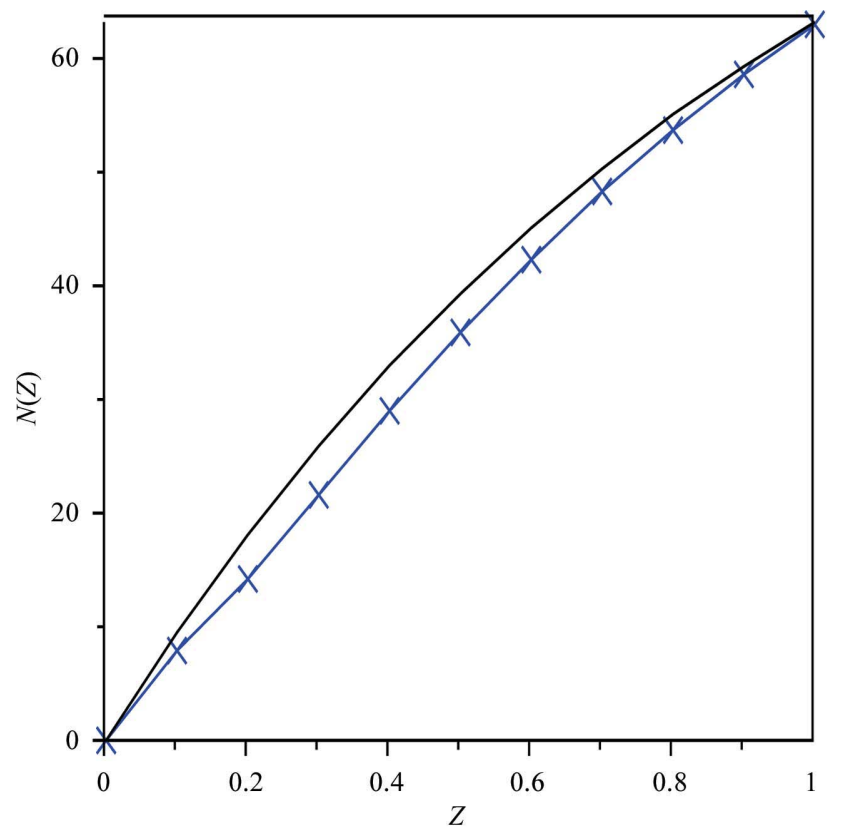

(a)
The equality of the $a$ and $c$ parameters, the apparent $C 222$ symmetry (as witnessed by the relatively low $R_{\text {merge }}$ factor in $C 222_{1}$ and the self-rotation function results) and the high crystallographic $R$ factors after molecular replacement raised the possibility that the crystal was twinned by the twinning operator $(l,-k, h)$, i.e. a twofold rotation about the axis diagonal between the $a$ and $c$ monoclinic directions.

Twinning is often detected by an analysis of the second moment of intensities of acentric data $\left\langle I^{2}\right\rangle /\langle|I|\rangle^{2}$ (Stanley, 1972; Yeates, 1997). A value of 2.0 is expected in the absence of twinning and of 1.5 in the case of a perfect twin. However, the calculated value of 1.972 in $X D S$ or 1.99 in TRUNCATE for the $P 2_{1}$ NGB data set suggested no twinning at all. Moreover, the observed cumulative intensity distribution of acentric data $N(z)=f(z)$ was only slightly sigmoidal, indicating a low degree of twinning at most (Fig. 1a). Another twinning indicator is $\left\langle|F|^{2}\right\rangle /\langle F\rangle^{2}$, which for acentric data should be 0.785 for untwinned and 0.865 for perfectly twinned data. For wild-type NGB,

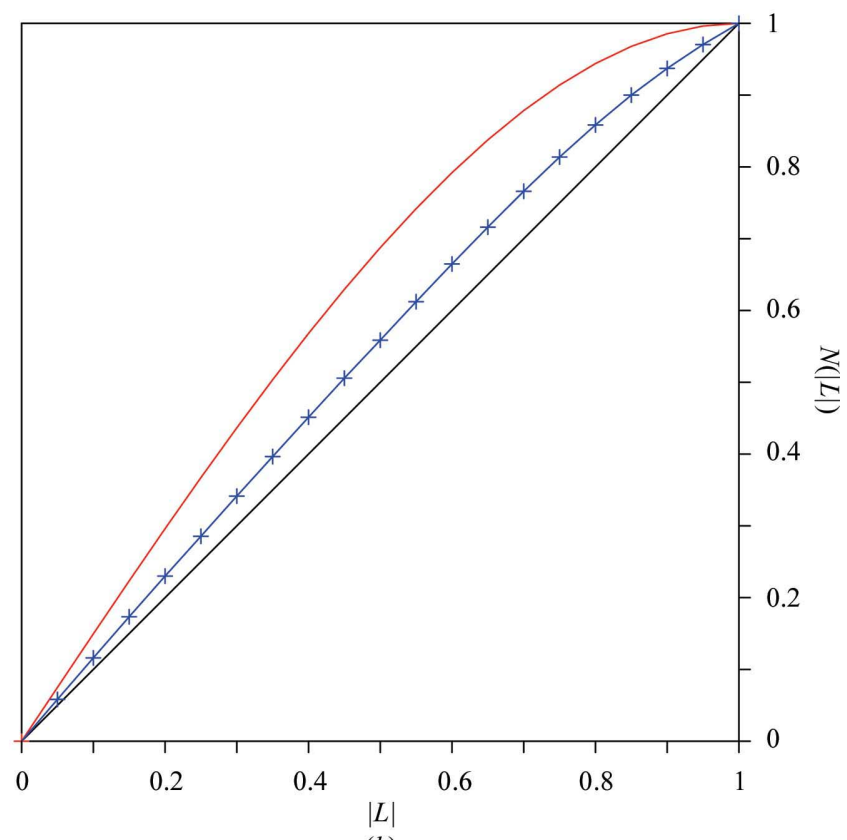

(b)

Figure 1

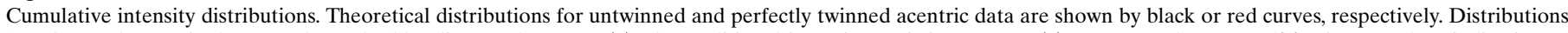

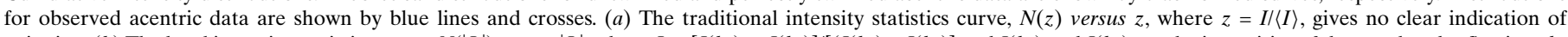

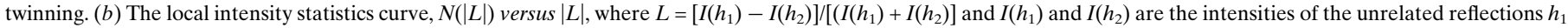
and $h_{2}$, falls between the curves expected for untwinned and perfectly twinned data. 
the value calculated in CNS (Brunger, 2007) is 0.834 , pointing to the presence of twinning with a high twinning fraction. Discrepancies between the two twinning indicators $\left\langle I^{2}\right\rangle /\langle|I|\rangle^{2}$ and $\left\langle|F|^{2}\right\rangle /\langle F\rangle^{2}$ have also been reported in similar cases (Rudolph et al., 2004; GolinelliPimpaneau, 2005). Indeed, it is known that the Stanley factor $\left\langle I^{2}\right\rangle /\langle|I|\rangle^{2}$ can behave abnormally and a newer test based on local intensity differences, which is insensitive to anisotropy and some kinds of pseudo-centring, has been implemented (Padilla \& Yeates, 2003). This test was performed for the NGB data set using DATAMAN (v.6.3 or above; PY_stats command) from the RAVE suite (Uppsala Software Factory). The cumulative probability distribution $N(|L|)$ versus $|L|$, where $L$ is defined as $\left[I\left(h_{1}\right)-I\left(h_{2}\right)\right] /\left[I\left(h_{1}\right)+\right.$ $\left.I\left(h_{2}\right)\right]$ and $I\left(h_{1}\right)$ and $I\left(h_{2}\right)$ are the intensities of the unrelated reflections $h_{1}$ and $h_{2}$, indeed gave an indication of twinning (Fig. $1 b$ ). The observed values of $\langle|L|\rangle$ and $\left\langle L^{2}\right\rangle$ were 0.457 and 0.286 , respectively, which are between the theoretical values for acentric perfectly twinned data ( 0.375 and 0.2 , respectively) and those for acentric untwinned data ( 0.5 and 0.333 , respectively) (Padilla \& Yeates, 2003). When a higher resolution range, also excluding the low signal-tonoise highest resolution data $(4-2.5 \AA)$, was considered, the behaviour of the local intensity statistics shifted only slightly towards that for perfect twinning, with observed values of $\langle|L|\rangle$ and $\left\langle L^{2}\right\rangle$ of 0.450 and 0.276 , respectively.

\subsection{Structure determination using twinned data}

The twin fraction was estimated with SHELXL using the twin operator $l,-k, h$. The refined twinning fraction of 0.496 is consistent with the low $R_{\text {merge }}$ value obtained in space group $C 222_{1}$ but was underestimated by the plots of intensity statistics (Fig. 1), which are only partway towards the curves expected for perfect twinning. This discrepancy has been observed previously and could result from the presence of NCS together with twinning (Rudolph et al., 2004;

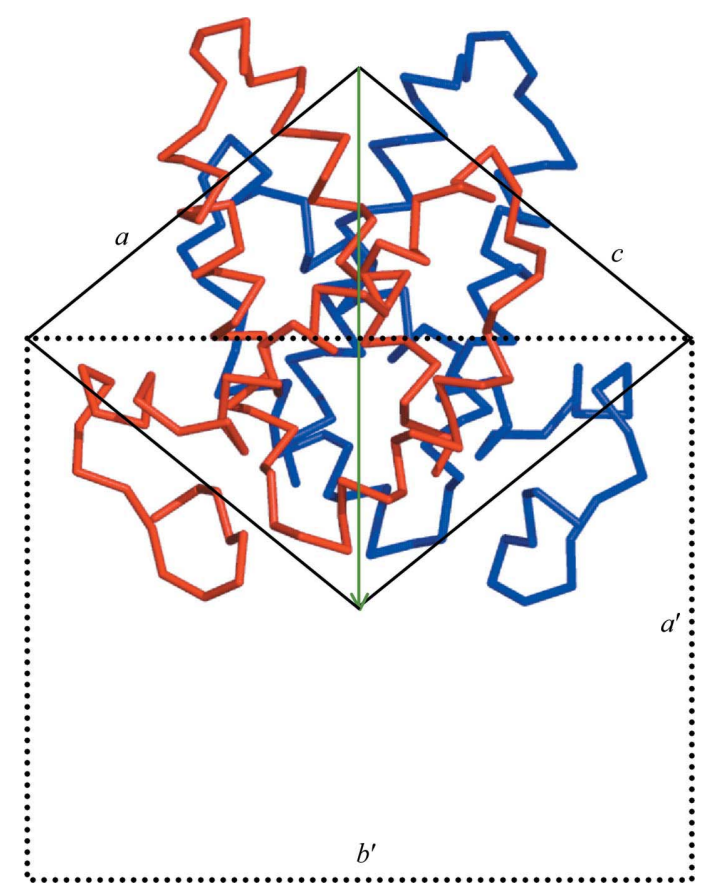

Figure 2

Geometric characteristics of the unit cell. The unit cell (black line) is projected along the $b$ axis. The effect of the twinning operator is to emulate pseudo-centring and the resulting $C 222_{1}$ cell $\left[a^{\prime}=2 a \cos (\beta / 2), b^{\prime}=2 a \sin (\beta / 2), c^{\prime}=b\right]$ is indicated as a dashed line. Each of the two NGB molecules (red and blue) in the asymmetric unit are shown as $\mathrm{C}^{\alpha}$ traces and the NCS axis is indicated in green.
Golinelli-Pimpaneau, 2005; Wittmann \& Rudolph, 2007). When twinning was taken into account, after 40 cycles of KonnertHendrickson conjugate-gradient steps the $R$ and $R_{\text {free }}$ values dropped to 0.339 and 0.397 , respectively, compared with 0.408 and 0.506 , confirming the diagnosis of pseudomerohedral twinning. The first steps of model building and refinement in SHELXL showed that the electron-density maps are sufficiently clear to allow the building of some missing regions of the model, which provides good evidence that the molecular-replacement solution is correct. However, there was no clear indication that taking twinning into account improves the quality of the map (data not shown). In fact, it is known that twin refinement improves statistics but only occasionally electron density when the twin and NCS axes are almost parallel (Murshudov, 2008), which is the case here. Indeed, the twofold NCS axis relating the two molecules in the asymmetric unit lies in the $a c$ plane, perpendicular to the crystallographic $b$ axis and almost intersecting it (Fig. 2). The two perpendicular axes generate a third axis perpendicular to them, emulating an orthorhombic unit cell (dashed line in Fig. 2). The geometry of the unit cell allows twinning, since the rotation of the unit cell about the ac plane diagonal leads to a superposition of the unit cells, with the interconversion of the $a$ and $c$ axes and inversion of the $b$-axis direction.

In summary, we report here a new case of a $P 2_{1}$ pseudo-merohedrally twinned crystal, which was observed in wild-type NGB. As frequently observed, twinning occurs in the presence of NCS, with the twofold NCS axis being parallel to one of the twin axes. Interestingly, we have noticed that the density maps were not noticeably improved on including the twin operator, which therefore cannot be a reliable criterion for detecting twinning. In contrast, a significant decrease in the crystallographic factors during refinement when twinning is taken into consideration appears to be a more definitive indicator that the data are twinned.

This work was supported by the CNRS, INSERM and the University of Paris XI. We thank Professor T. Burmester and T. Hankeln (University of Hamburg/Mainz) for the NGB plasmid, A. Legros for crystallization trials, A. Thompson for help in data collection and R. Herbst-Irmer for advice.

\section{References}

Ban, N., Nissen, P., Hansen, J., Capel, M., Moore, P. B. \& Steitz, T. A. (1999). Nature (London), 400, 841-847.

Barends, T. R. M. \& Dijkstra, B. W. (2003). Acta Cryst. D59, 2237-2241.

Brett, T. J., Legendre-Guillemin, V., McPherson, P. S. \& Fremont, D. H. (2006). Nature Struct. Mol. Biol. 13, 121-130.

Breyer, W. A., Kingston, R. L., Anderson, B. F. \& Baker, E. N. (1999). Acta Cryst. D55, 129-138.

Brunger, A. T. (2007). Nature Protoc. 2, 2728-2733.

Burmester, T., Weich, B., Reinhardt, S. \& Hankeln, T. (2000). Nature (London), 407, 520-523.

Collaborative Computational Project, Number 4 (1994). Acta Cryst. D50, 760-763.

Declercq, J.-P. \& Evrard, C. (2001). Acta Cryst. D57, 1829-1835.

Dewilde, S., Kiger, L., Burmester, T., Hankeln, T., Baudin-Creuza, V., Aerts, T., Marden, M. C., Caubergs, R. \& Moens, L. (2001). J. Biol. Chem. 276, 38949 38955.

Dewilde, S., Mees, K., Kiger, L., Lechauve, C., Marden, M. C., Pesce, A., Bolognesi, M. \& Moens, L. (2008). Methods Enzymol. 436, 341-357.

Evans, P. (2006). Acta Cryst. D62, 72-82.

Golinelli-Pimpaneau, B. (2005). Acta Cryst. D61, 472-476.

Greenberg, D. A., Jin, K. \& Khan, A. A. (2008). Curr. Opin. Pharmacol. 8, 20-24.

Hamburger, A. E., West, A. P. Jr \& Bjorkman, P. J. (2004). Structure, 12, 1925 1935. 


\section{short communications}

Hamdane, D., Kiger, L., Dewilde, S., Green, B. N., Pesce, A., Uzan, J., Burmester, T., Hankeln, T., Bolognesi, M., Moens, L. \& Marden, M. C. (2003). J. Biol. Chem. 278, 51713-51721.

Hamdane, D., Kiger, L., Dewilde, S., Green, B. N., Pesce, A., Uzan, J., Burmester, T., Hankeln, T., Bolognesi, M., Moens, L. \& Marden, M. C. (2004). Micron, 35, 59-62.

Hamdane, D., Kiger, L., Hoa, G. H., Dewilde, S., Uzan, J., Burmester, T., Hankeln, T., Moens, L. \& Marden, M. C. (2005). J. Biol. Chem. 280, 3680936814.

Heitmann, D. \& Einsle, O. (2008). Acta Cryst. D64, 993-999.

Ishikawa, H., Kim, S., Kwak, K., Wakasugi, K. \& Fayer, M. D. (2007). Proc. Natl Acad. Sci. USA, 104, 19309-19314.

Ito, N., Komiyama, N. H. \& Fermi, G. (1995). J. Mol. Biol. 250, 648-658.

Kabsch, W. (1993). J. Appl. Cryst. 26, 795-800.

Larsen, N. A., Heine, A., de Prada, P., Redwan, E.-R., Yeates, T. O., Landry, D. W. \& Wilson, I. A. (2002). Acta Cryst. D58, 2055-2059.

Lehtiö, L., Fabrichniy, I., Hansen, T., Schönheit, P. \& Goldman, A. (2005). Acta Cryst. D61, 350-354.

Murshudov, G. N. (2008). CCP4 School: From Data Processing to Structure Refinement and Beyond. Argonne National Laboratory.

Padilla, J. E. \& Yeates, T. O. (2003). Acta Cryst. D59, 1124-1130.
Pesce, A., Bolognesi, M., Bocedi, A., Ascenzi, P., Dewilde, S., Moens, L., Hankeln, T. \& Burmester, T. (2002). EMBO Rep. 3, 1146-1151.

Pesce, A., Dewilde, S., Nardini, M., Moens, L., Ascenzi, P., Hankeln, T., Burmester, T. \& Bolognesi, M. (2003). Structure, 11, 1087-1095.

Rudolph, M. G., Wingren, C., Crowley, M. P., Chien, Y. \& Wilson, I. A. (2004). Acta Cryst. D60, 656-664.

Schmidt, M., Giessl, A., Laufs, T., Hankeln, T., Wolfrum, U. \& Burmester, T. (2003). J. Biol. Chem. 278, 1932-1935.

Sheldrick, G. M. (2008). Acta Cryst. A64, 112-122.

Stanley, E. (1972). J. Appl. Cryst. 5, 191-194.

Storoni, L. C., McCoy, A. J. \& Read, R. J. (2004). Acta Cryst. D60, 432 438

Sultana, A., Alexeev, I., Kursula, I., Mäntsälä, P., Niemi, J. \& Schneider, G. (2007). Acta Cryst. D63, 149-159.

Sun, Y., Jin, K., Peel, A., Mao, X. O., Xie, L. \& Greenberg, D. A. (2003). Proc. Natl Acad. Sci. USA, 100, 3497-3500.

Vinck, E., Van Doorslaer, S., Dewilde, S. \& Moens, L. (2004). J. Am. Chem. Soc. 126, 4516-4517.

Wittmann, J. G. \& Rudolph, M. G. (2007). Acta Cryst. D63, 744-749.

Yang, F., Dauter, Z. \& Wlodawer, A. (2000). Acta Cryst. D56, 959-964.

Yeates, T. O. (1997). Methods Enzymol. 276, 344-358. 